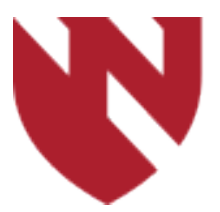

October 2021

\title{
Anesthetic Considerations for Non-Cardiac Surgery in an Adult Patient with Right Atrial Isomerism
}

\author{
Sagar Bansal \\ University of Nebraska Medical Center \\ Rebecca A. Aron \\ University of Nebraska Medical Center
}

Tell us how you used this information in this short survey.

Follow this and additional works at: https://digitalcommons.unmc.edu/gmerj

Part of the Higher Education Commons, and the Medicine and Health Sciences Commons

\section{Recommended Citation}

Bansal, S., , Aron, R. A. Anesthetic Considerations for Non-Cardiac Surgery in an Adult Patient with Right Atrial Isomerism. Graduate Medical Education Research Journal. 2021 Oct 04; 3(1). https://digitalcommons.unmc.edu/gmerj/vol3/iss1/33 


\section{Anesthetic Considerations for Non-Cardiac Surgery in an Adult Patient with Right Atrial Isomerism}

\section{Creative Commons License}

\section{c) (1) $\Theta($}

This work is licensed under a Creative Commons Attribution-Noncommercial-No Derivative Works 4.0 License. 


\section{Breast Conservation in Low- and Middle-Income Countries: Global Trends in Breast Cancer Care Philip McCarthy', Jessica Maxwell2, Benjamin Acton ${ }^{1}$ \\ ${ }^{1}$ University of Nebraska Medical Center, College of Medicine, Department of Surgery, Division of General Surgery \\ ${ }^{2}$ University of Nebraska Medical Center, College of Medicine, Department of Surgery, Division of Surgical Oncology}

Mentor: Jessica Maxwell

Program: General Surgery Residency

Type: Systematic Review

Background: The safety and efficacy of breast conserving therapy has been well established and has become mainstay treatment for appropriate invasive and in situ breast cancer. This review is to determine the utilization of BCT in LMIC globally, and to assess factors contributing to surgical choice and use of adjuvant RT in BCS candidates.
Methods: Systematic review of breast conserving surgery in low- and middleincome countries was performed using Cochrane Library, EMBASE, and MEDLINE. After removing duplicates, 3,208 papers remained, with only 165 studies meeting inclusion criteria.

Results: The majority of high yield research into BCT came from China, India, Brazil, Turkey, and Egypt, with China having the most relevant papers (38). Given greater access to resources, these middle-income countries had treatment options similar to higher income countries. On the other end of the spectrum, lower income countries such as Yemen, Zambia, and Nigeria are largely unable to perform BCT either due to lack of resources or greater presentation of late-stage disease.

Conclusions: Within the Low- and MiddleIncome country paradigm, middle income countries are able to offer breast conservation surgery at higher levels compared to lowincome countries. Difference in utilization of BCT is largely due to disparities in resource availability in middle income countries versus lower income countries.

https://doi.org/10.32873/unmc.dc.gmerj.3.1.017

\section{Anesthetic Considerations for Non-Cardiac Surgery in an Adult Patient with Right Atrial Isomerism Sagar Bansal ${ }^{1}$, Rebecca Aron ${ }^{1}$ \\ ${ }^{1}$ University of Nebraska Medical Center, College of Medicine, Department of Anesthesiology}

Mentor: Rebecca Aron

Program: Department of Anesthesiology

Type: Case Report

Background: HS has an estimated incidence of 1 in 6000 to 1 in 20000 live births. Right atrial isomerism involves failure of the embryo to develop a normal left right asymmetry and presents as complex cardiac and extracardiac abnormalities. It results in bilateral right atria with an absence of left-sided structures. Presence of intracardiac shunts makes the use of IV air filters to decrease air embolism important. In this patient, a right sided arterial line was selected given a left sided BT shunt. BT

\section{This Is Why You Take Your Vitamins}

Alison Bauer ${ }^{1}$, T. Jason Meredith ${ }^{1}$

${ }^{1}$ University of Nebraska Medical Center, Department of Family Medicine

Mentor: Jason Meredith

Program: Family Medicine

Type: Case Report

Background: This case report demonstrates the importance of long-term follow up and potential morbidity associated with vitamin shunt flow was optimized by maintaining euvolemia and preventing increases in pulmonary vascular resistance (e.g., avoiding hypoxia, hypercarbia and sympathetic stimulation). General anesthesia was chosen to better control oxygenation and ventilation. Excessive PEEP and low airway pressures were ensured. Given obligate mixing, baseline oxygen saturations in the 70s were maintained. Given asplenia, antibiotic prophylaxis was given and strict sterile conditions during procedures were ensured. Stress steroids were given for panhypopituitarism. Aspirin was continued given the thrombosis risk associated with erythrocytosis.

Case: To discuss anesthetic considerations in a $39 \mathrm{y} / \mathrm{M}$ with Heterotaxy Syndrome (HS), right atrial isomerism, pulmonic, Blalock Taussig (BT) shunt, asplenia, congenital panhypopituitarism, chronic cyanosis with clubbing and secondary erythrocytosis, with refractory hemorrhoids who presented for surgical hemorrhoidectomy. Baseline arterial oxygen saturations were in mid 70 s and hemoglobin was $23.1 \mathrm{mg} / \mathrm{dl}$.

Conclusion: Anesthetic management in patients with HS requires understanding of the cardiovascular anatomy to determine hemodynamic goals, limb selection for line placement and optimal treatment.

https://doi.org/10.32873/unmc.dc.gmerj.3.1.026 minimal improvement after icing/NSAIDs. He denied previous knee injuries. PSH was notable for gastric sleeve procedure 7 years prior. He reported being non-compliant with his post-procedure vitamin recommendations and had not been seen for follow-up regularly. On exam, tenderness to palpation along both medial and lateral joint lines and over the 